\title{
Corporate Culture as Behavioural Risk Management: The Hurdle of Unshared Knowledge
}

\author{
Joan Nix \\ Associate Professor of Economics \\ Department of Economics \\ Queens College and the Graduate Center \\ City University of New York
}

Compensation schemes play a significant role in explaining employee behavior. However, the recent financial crisis provides many examples where compensation schemes created perverse incentives that favored short-run gains at the expense of long-run viability. The penalties paid, as well as, the amount of attention given to misdeeds by employees has renewed interest in the need for corporate culture to encourage proper conduct. A weakness with this approach is that corporate culture depends on shared knowledge. Decisions to keep silent challenge the efficacy of norms as widely shared rules of conduct that corporate culture attempts to inculcate. Our main conclusion is that the presence of strategic silence underscores a major problem with corporate culture's role in behavioral risk management. In searching for a remedy, digital tokens as incentives merit serious consideration.

Keywords: Prisoner's Dilemma, norms, corporate culture

\section{JEL codes: B40, D9, L29}

\section{Introduction}

"When we look at companies' web pages, we find that 85 percent of the S \& P 500 companies have a section (sometimes, even two) dedicated to-what they call-'corporate culture,' i.e. principles and values that should inform the behavior of all firms' employees." "In the face of misconduct, mistakes, and poor decision-making among firms during the financial crisis there is renewed interest in corporate culture as a set of formal and informal rules that incentivize behavior. The losses from bad behavior in the financial sector alone are staggering. One recent estimate from the Boston Consulting Group is that since the financial crisis firms in the financial industry have paid upwards of 350 billion dollars in fines and penalties for misconduct. ${ }^{2}$ A sign of how important it is that firms take the issue of employee conduct seriously is found in the G30 Report that recommends boards form separate committees to look at culture and conduct. ${ }^{3}$ It is not only publically held firms that are addressing issues of culture and conduct. Recently, privately held Fidelity Investments with over two trillion dollars under management is considering "rehabilitating the culture" towards a more "team-based" approach to asset management in response to allegations of misconduct. ${ }^{4}$

The use of incentives such as promotions and compensation to replace bad cultures with good ones faces a specific conflict. Curating bad news about behavior can be harmful to the individuals in possession of it. Firms must reckon with the possibility that employees have knowledge of value to the company that for various reasons they are not revealing. ${ }^{5}$ The starting point for our analysis is that blind trust in corporate culture as a mechanism to generate "proper behavior" is unwarranted precisely because it depends on shared knowledge. Cremer (1993) considered corporate culture as the stock of shared knowledge among trustworthy and honest individuals.

It is this assumption that we question.

\footnotetext{
${ }^{1}$ Guiso, Sapienza, Zingales (2013), p.2.

${ }^{2}$ See Reuters Staff (2017).

${ }^{3}$ See $\mathrm{G} 30$ report (2013).

${ }^{4}$ KrouseandGrand (2108) WSJ.

${ }^{5} \mathrm{We}$ are not considering knowledge that reflects expertise and is not easily communicated to others as knowledge that needs to be revealed to create value. In that case it is the specialization behind knowledge that creates value. Instead our focus is on knowledge that is deliberately held back but has value when others find out about it.
} 
The 2007-2009 financial crisis is a powerful example of the harm done by silence. Many firms did not truthfully admit to their credit problems until a bailout was needed. ${ }^{6}$ Consider the example of Bear Stearns, a firm that loaded up on mortgage related assets while specifically denying that it had done so. "In August 2007, management denied that the bank had serious exposure to mortgage related securities." The bankruptcy of Lehman Brothers sent shock waves around the world, but leading up to its demise were many decisions deliberately hidden from view. "Indeed, as we now know, Lehman was going to extraordinary efforts, including shady accounting practices, to hide its leverage even after the financial crisis started in August 2007.", Unexpressed concerns about credit quality caused serious harm that had devastating effects felt across countries. ${ }^{9}$ Of course, sanctions or punishments for mistakes affect behavior. In a recent survey done by the Banking Standards Board, thirty percent of the respondents agreed with the statement "If I raised concerns about the way we work, I would be worried about the negative consequences for me." ${ }^{10}$ However, designing incentive schemes that completely eliminate social sanctions for mistakes is not a realistic solution. ${ }^{11}$ The question thus arises: Can the bad consequences be mitigated through the use of incentives to reveal information central to the firm's survival in a timely way?

The focus of our analysis is on the need for a firm to curate bad news from the participants responsible for it. We use a prisoner's dilemma game to investigate the conditions when curation of bad news leads participants to reveal it. In place of two prisoners from whom the authorities attempt to curate information about a crime, ${ }^{12}$ there are two coworkers who must choose to either cooperate with each other and remain silent about a problem, or to engage in honest talk and reveal the problem to others. We work through a simple two-player example with selfinterested players, and then consider what can happen in the presence of an "old boys" coalition. Coalition loyalty captures expected career benefits from networking and cooperation may be conditioned on these benefits. ${ }^{13}$

In the presence of strategic silence a firm could wait it out and let cooperation decay over time. Another option is to introduce norms to discourage strategic silence by means of sanctions and punishments. Finally we consider crowd sourcing reputation management by deploying technology in the form of digital assets that operate as rewards. Our conclusion is the third option has the greatest potential for disincentivizing strategic silence. A central reason is that silence is difficult to interpret-a silent individual may be listening and learning from the speaker, or may simply have nothing of importance to say. It is this blind spot around silence that makes an honesty norm difficult to enforce under the second option. As for the first option it is not very appealing: research on repeated prisoner's dilemma games show that it can take many rounds for cooperation to decay, leaving time for damages from silence to spread. ${ }^{14}$

In short, strategic silence harms the effectiveness of corporate culture as behavioral risk management. ${ }^{15} \mathrm{We}$ propose an alternative platform for rewards in the form of digital tokens created by software with the capacity to develop a tokenization of actions that aligns the interests of workers with a firm's goals in ways that are more tangible than loose commitments to norms that embody a firm's corporate culture.

\footnotetext{
${ }^{6}$ SeeMishkin (2011).

${ }^{7}$ Chaplinsky (2008, p.12.)

${ }^{8}$ Mishkin (2011 p. 62.)

${ }^{9}$ De hassandVaulteron (2012).

${ }^{10}$ Banking Standards Board, AnnualReview 2016/2017.

${ }^{11}$ Thefounder of Etsy refers to silence about details regarding mistakes or mishaps as "cover your ass" engineering. See Allspan(2012) for more on this type of culture. The problem with a "give it to me straight" culture is that while mistakes are useful for learning, rewarding mistakes is a questionable incentive in terms of effectiveness. Reforms to "clawback" bonuses enacted after the financial crisis suggest that some harm to the individual from mistakes or mishaps is needed to round out a system of incentives.

${ }^{12}$ SeeLuceandRaiffa (1957).

${ }^{13}$ Shue (2013) offers evidence of the importance of social interactions and peer effects on managerial decision-making. See also Willmer's article in Bloomberg (2017) about the claims that such a club exists at Fidelity and harms women's chances of promotion.

${ }^{14}$ SeeNowak(2006).

${ }^{15}$ Lo (2016) employs the term "behavioral risk management" for corporate culture arguing that term has a more practical orientation directing analysis towards policies that are consistent with specific goals of corporate culture.
} 
As bitcoin was introduced at least in part to solve the problem of trust in a centralized monetary authority ${ }^{16}$ programmable utility tokens designed for intra-firm use have the potential to reinforce the institutional trust needed for corporate culture to function effectively as a guide for proper behavior. The paper's roadmap is as follows: Section 2 provides a literature review. Section 3 illustrates the harm from holding back valuable knowledge through an application of a prisoner's dilemma game, Section 4 follows with a discussion of issues that arise from relying on a norm of honesty to discourage unshared knowledge. A set of design features needed to crowd source reputation management through digital tokens is provided in section 5. Concluding comments follow in section 6 .

\section{Background}

Research that unmoored the inner workings of firms from the direct influence of market forces provides the groundwork for corporate culture to walk in as a potent influence on employee behavior. Two strands of research stand out for calling attention to the need for something else besides the market and industry structure to explain a firm's performance. The transaction cost analysis of the firm set forth in the seminal research of Williamson $(1975,1983)$ provides a perspective on the organization of work and the need for authority relations that at least on a conceptual level views the firm as a separate entity not completely beholden to market forces. The contractual theory of the firm also represents a significant move away from the black box view of the firm where firms facing market pressures maximize profits. Major contributions to the contractual theory of the firm are found in Coase (1937), Archian and Demsetz (1972), Jensen and Meckling (1976) and Fama and Jensen (1983). The contractual theory of the firm provides the intellectual roots for seminal research on agency problems within an organization that initially had as its focus the agency costs between owners and top managers. ${ }^{17}$

Agency problems made clear the need for an internal control system in the form of "organizational rules of the game" that includes allocation of decision rights, performance reviews, and rewards and punishments. Organizational rules of the game may be considered equivalent to a firm's corporate culture. ${ }^{18}$ The perspective of corporate culture as rules of the organization game focuses attention on defining an effective corporate culture and discovering what types of rules equate to it.

One way to achieve a productive corporate culture is through influencing preferences of employees so that they internalize the company's goals as their own and will act accordingly even when facing discretionary and unmonitored decisions. Instilling values in employees that result in changes in utility functions is modeled by Lazear (1995). The role of identifying with an organization that serves to enhance utility is found in Akerlof and Kranton $(2000,2005)$. That corporate culture also has a role to play in modifying preferences and internalizing norms is found in Hodgson (1995). Hamilen (2012) employs game theoretic models to illustrate the strength and weaknesses of corporate culture in its role as an arbitrator of individual actions.

Many studies provide evidence of failures in the transmission of values. Robertson (2011) finds that weak internal controls contributed to the 2007-2009 financial crisis by allowing aggressive lending to go unchecked, along with failures and weaknesses in securitization and due diligence. Moosa (2007) defines operational risk to include the behavior of employees as a major risk for banks' solvency. The risk of employee behavior is not dependent upon a critical mass of employees behaving badly. There are many examples where one or a few employees caused significant firm damage. ${ }^{19}$

Corporate culture plays an important role in research by McNulty and Akhigbe (2015). They find that the litigation costs of banks are a significant factor for predicting future financial performance. Weak internal controls associated with ineffective corporate cultures are found to accompany poor performance.$^{20}$ There is also recent research that offers support for the view that consumers dislike and disapprove of bad behavior at least among banks and will take their deposits elsewhere.

\footnotetext{
${ }^{16}$ See paper by Nakamoto (2009) that introduces bitcoin.

${ }^{17}$ See Eisenhardt (1989) for a comprehensive review.

${ }^{18}$ Brickley, Smith and Zimmerman (2015) use the term organizational architecture as interchangeable with corporate culture.

${ }^{19}$ For example, see Leeson (1996) for an in depth look at the demise of Barrings Bank. The failure to supervise one key employee who apparently did not internalize the long-run interests of the company resulted in a 1.3 billion dóllar loss and its collapse.

${ }^{20}$ They consider data from 2002 to 2006 for legal expenses and use performance figures from 2007 and 2008.
} 
A recent paper finds "total deposit growth decreases when banks are involved in tax invasion (e.g. Panama Papers Leak), Corruption (Libor Scandal), and environmental scandals." ${ }^{21}$ According to Lo (2016) corporate culture is important for determining the set of risk priorities for a firm. However, as the financial crisis illustrates risk priorities can go awry though deliberate silence. For example, Lehman Brothers culture of concealment played a role in its downfall as problems were deliberately hidden from regulators, investors, and even other employees.

\section{Model: The PD Game}

Modern corporations face coordination challenges and corporate culture helps coordinate behavior among employees. ${ }^{22}$ A significant coordination challenge occurs when employees do not share knowledge. There are knowledge silos inhabited by different groups. A factory worker may know how a specific machine tool operates, but has little knowledge of the demand forecasting equation used to estimate how many machine tools are needed. Executives may have a deep understanding of the firm's broad based strategic goals that few rank and file employees know about in any meaningful way. But besides the obvious explanation of specialization and rank to explain why knowledge is not shared among employees there is another more troubling explanation. Knowledge that has value to the firm may be deliberately held back through what we refer to as "strategic silence," motivated by a fear of retaliation or punishment.

The decision either to share knowledge that is harmful for the individual in possession of it, or to remain silent, represents a class of problems that is captured by the well-known prisoner's dilemma game. The original version of the pd game represents a strategic interaction involving a decision to either remain silent about a crime, or confess and provide evidence that authorities desire. ${ }^{23}$ In the original version cooperation is good for the prisoners but not for the larger society. Likewise, strategic silence serves as the cooperative strategy choice that is good for the coworkers but not for the firm.

A simple example illustrates the conflict involved with sharing knowledge. Alex and John are two loan officers evaluating whether their firm should approve or reject a loan application. They have a checklist to follow that includes obtaining proof of income, credit score, and outstanding debts for each applicant. They both know that if they do not approve this loan they will not make their target volume of loans for the period. Alex and John also recognize a number of red flags in the application. Their Boss has a different performance target that is to minimize loans that go into default. If the Boss is informed of the red flags, he will not approve the loan and the coworkers will miss their target. If the coworkers remain silent about the red flags the loan is approved and they make their target. ${ }^{24}$

A key feature of the example is that the loan represents a type of project that has positive short-term effects for a firm but negative long-term effects. If approved the loan's long-term performance is not immediately obvious as long as payments are made to service the debt. Assume years will pass before payments are missed and the loan defaults. The coworkers will not be held responsible for missed payments years down the road. Perhaps Alex and John have moved on to greener pastures or by the time payments are missed the environment has changed so that other reasons beyond what Alex and John knew will be accepted as an explanation for the default. There are too many moving pieces to connect this one loan default to the approval process.

In order to spotlight the conflict over whether to reveal the red flags, we initially narrow our focus to a one period two-player prisoner's dilemma game. The coworkers realize immediately that it is a bad idea. However, approval of one lousy loan does not cause reputational damage or cash flow damage to the firm. Its stock price does not reflect such information. If both coworkers do not reveal the red flags, then the first period loan repayment is made. So when they keep quiet about the red flags no penalty awaits them and they have made their target. However, if either they both confess that the loan is a bad idea or only one confesses, they do not make their performance target for the period.

\footnotetext{
${ }^{21}$ Homanen (2018).

${ }^{22}$ See Kreps (1990) for a game theoretic example where corporate culture helps determine the equilibrium to play in games with multiple equilibria.

${ }^{23}$ As described in Luce and Raiffa (1957) who atribute the original version to A.W.Tucker.

${ }^{24}$ There is no opportunity for a whistleblower (apart from the coworkers) to come forward as the red flags are only known to the coworkers. 
Of course, mutual cooperation where both coworkers remain quiet is inconsistent with the firm's corporate culture because strategic silence regarding the high default risk of the loan violates a major purpose of corporate culture, which is to incentivize proper conduct consistent with the long-run interests of the firm.

The standard pd game is illustrated in Table 1 with a two- player game, the two strategy choices Silent and Talk refer to cooperate (strategic silence) and defect (talk). The payoffs represent the bonus the coworkers receive from the various strategy choices. ${ }^{25}$ If they both reveal red flags and the loan is not approved, they do not make their numbers, and receive a bonus of $\mathrm{P}$ (punishment payoff). If one coworker comes forward and reveals the truth about the loan applicant, he receives an extra bonus of $\mathrm{T}$ (temptation payoff), while the coworker who remained silent is left with less than the punishment payoff, $\mathrm{S}$ (sucker payoff). We assume that the punishment payoff represents a cut in last year's bonus, while the sucker payoff represents an even bigger cut. The reward payoff(R) is an increase over last year's bonus payoff, while the temptation payoff represents an even larger increase. Following, Nowak(2006) $\mathrm{R}=$ reward, $\mathrm{T}=$ temptation, $\mathrm{S}=$ sucker, and $\mathrm{P}=$ punishment. The prisoner's dilemma game is where: $\mathrm{T}>\mathrm{R}>\mathrm{P}>\mathrm{S}$. The relationship among the bonus payments is consistent with the views expressed by the SEC chairperson at the time of the financial crisis. "Many major financial institutions created asymmetric compensation packages that paid employees enormous sums for short-term success, even if these same decisions result in significant long-term losses or failures for investors and taxpayers." ${ }^{, 6}$

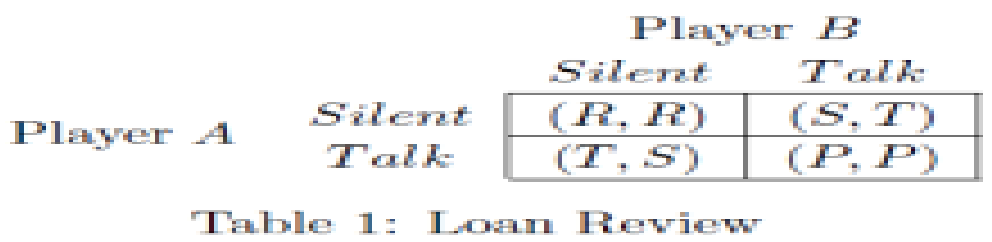

Since $T>R$ and $P>S$, talk is a dominant strategy. This implies that the coworkers reveal the red flags, and the loan is not approved,

The rational decision is Pareto inferior for the players but efficient for the firm. The temptation payoff to "rat out" your coworker is critical for each self-interested coworker to decide to reveal the truth about the loan's default risk. In light of the broader goals of corporate culture, while the solution is in the firm's interest negative spill over effects may be present. Sustaining through defection in a pd game the sharing of knowledge by having coworkers turn against each other conflicts with the prosocial values of solidarity and comaraderie typically found in the mission statements of companies. Since in this application the foundation for shared knowledge is squealing on each other the collective behavior that emerges from pd interactions when coworkers rat each other out conflicts with building a "virtuous corporate culture.",

The example assumes that the only source of worker benefit is the bonus payments. However, the coworkers may belong to a network where they establish beneficial connections with other members of the network. In this way, their relationship to each other establishes an independent source of benefits. The extra benefits will result in a modification of the payoffs from cooperation. "The utility of the terminal nodes sums up all the normatively relevant consideration." 28 The payoffs from cooperation increase because by choosing to cooperate coworkers protect each other and help each other make their target performance goals. ${ }^{29}$ Their coalitional loyalty to each other potentially serves their future needs for mentorship, job referrals, introduction to important people, and general advice that helps their career prospects. For these reasons, we can not a priori rule out the possibility that coalitional loyalty provides another source of benefits.

\footnotetext{
${ }^{25}$ See Holmstrom (1999) and Meyers and Vickers (1997) on the importance of career concerns for managers. See Benabon and Tirole (2016) on the importance of the "bónus culture." Bonus amounts are a critical determinant of employee importance and significance to the firm.

${ }^{26}$ The Financial Crisis Report (2011, p. 64.)

${ }^{27}$ Dudley (2018).

${ }^{28}$ Gaus $(2008$, p.116.)

${ }^{29}$ See Dovidio and Gaertner (2010) for a discussion of Intergroup bias. See Kanter(1993) about the influence ofgroups in corporations. There is a vast literature ongroup identity and group selection. See Hammond and Alexrod (2006), Masuda (2012) and Garcia and VandenBergh (2011), Akerlof and Kranton (2005).
} 
The additional benefit may be substantial enough to lead both players to choose cooperation or strategic silence. ${ }^{30}$ If payoffs are sufficiently increased by coalitional loyalty, then the rational decision is Pareto Optimal for the players, but inefficient for the firm.

The unsatisfactory state of affairs for corporate culture as a guide to proper behavior when strategic silence is present as a strategy choice is that either the players rat each other out and share knowledge with the boss or remain silent because of coalitional loyalty based on an old boys' network. Perhaps these obstacles towards building a positive corporate culture are not that serious because our example is based on a one shot version of the pd game. Since there is a great deal of research that extends the pd game to a repeated context, ${ }^{31}$ we borrow from this research to examine what is possible in a repeated context.

A well-known result based on the basic evolutionary model with no formal reputation system in place is that cooperation decays over time. The number of periods for its decay depends both on the initial proportions of cooperators and defectors, as well as, the temptation payoff relative to the reward payoff. ${ }^{32}$ However, this "wait and see" attitude offers little comfort to firms that need an effective corporate culture in the present. Also we cannot rule out the possibility that in the repeated context with coalitional loyalty as a source of benefits there may be an equilibrium in which the frequency of cooperators versus defectors produces a culture of concealment where the frequency of cooperators in equilibrium is larger than that of defectors. The financial crisis taught many lessons and an important one is that repeated interactions among a small group do not necessarily produce outcomes in the larger group's interest. ${ }^{33}$ A firm could hope that even in the presence of repeated interactions not one of the mechanisms that sustain cooperation kicks in precluding strategic silence. But then we are back to the one-shot outcome with self-interested players squealing on coworkers and thereby adding to common knowledge. Incentivizing untrustworthiness provides a questionable moral path for building a positive corporate culture.

Since the unsatisfactory state of affairs continues in the repeated context perhaps other types of solutions such as changing compensation schemes by paying workers more for greater effort is the way forward. But not when it is the anticipated benefits of silence and not effort motivating decisions. Of course, in the presence of a norm of honesty such worries are misplaced. If for example an honesty norm were functioning the utility payoffs would be affected by silence in such a way as to contradict the rank order of payoffs that defines the pd game. In the next section, we consider whether worries about corporate culture's capabilities to communicate widely emulated social rules of conduct are misplaced because of an honesty norm.

\section{Strategic Silence: A Hurdle for Norm Enforcement}

An honesty norm faces obstacles that stem from the fact that cognitive coordination surrounding norm enforcement is more difficult when strategic silence is present. For purposes of illustration assume there is a group of workers in the firm who have a strong intrinsic preference for honest behavior and are immune from situational influences that may encourage dishonesty. ${ }^{34}$ This group disapproves of strategic silence because it violates the norm of honesty. How useful are the members of this group in their role as bystanders? Their first hurdle is figure out what criteria to use to separate strategic silence from harmless silence that may reflect simply listening to others speak. A bystander to strategic silence does not immediately see the harm done and therefore, is not triggered towards punishment or sanctions by his moral instincts and intuitions. Bystanders do not even know if a transgression has occurred, never mind the question of its magnitude. ${ }^{35}$ There are many explanations as to why coordinated punishment is difficult to achieve, ${ }^{36}$ but the absence of a guilty party makes even the thought of a trial hard to imagine.

\footnotetext{
${ }^{30}$ There is much research to back up loyalty as a source of benefits. Haidt (2007) points out the cross-cultural importance of ingoup and outgroup identification and loyalty. See Salz Review (2013, p.197) for an independente review of Barclay's business practices. "No one in our group speaks out about concerns of what may be right or wrong for fear of being seen to be disloyal."

${ }^{31}$ Axelrod (1998) for discussion of the success of the tit for tat strategy in sustaining cooperation in repeated pd games and Nowak (2006) for a review of the mechanisms that sustain cooperation in a repeated pd game.

${ }^{32}$ Nowak (2006)

${ }^{33}$ Financial InquiryReport (2011).

${ }^{34}$ Gibson, Tannerand Wagner (2015).

${ }^{35}$ See Hoffman, Yoeli, Dalkiran, and Nowak (2018) for an explanation of why categorical norms are easier to sanction and support as an equilibrium outcome than threshold norms.

${ }^{36}$ See Ohtsuki and Iwasi (2009) and Hoffman, Yoeli, Dalkiran, and Nowak (2018). 
A signal of trustworthiness for third party punishment depends on others recognizing that someone has done something wrong. ${ }^{37}$ In the case of the pd game, detection can only succeed when a coworker turns in evidence that the loan is a bad idea. In the absence of a recognizable transgression moral illumination through corporate culture is of limited capacity since imposing sanctions and punishments is difficult without a recognizable transgression. Any loss in utility from norm violation will not materialize unless a violation can be detected. ${ }^{38}$ The unobservable threshold for detecting differences between strategic silence and harmless silence precludes emergence of a categorical norm such as detect and punish strategic silence. ${ }^{39}$ This operates as a brake on moving strategic silence into the open field of common knowledge.

Descriptive norms face a different set of challenges. For example, consider programs devoted to energy conservation that describes the average electricity use in neighborhoods. ${ }^{40}$ Making public the consumption patterns of the neighborhood enforces a descriptive norm. But how would this type of norm work for strategic silence when the frequency of strategic silence is unknown?

"Geertz is making the methodological point that culture is not about 'unobservable mental states' but about 'socially established structures of meaning' by which people communicate and are therefore available for analysis and understanding." ${ }^{41}$

The traditional tool kit of corporate culture includes dis-incentivizing strategic silence by ramping up messages about the importance of truth-telling. An example of institutionalizing a corporate culture of "Radical Transparency" is found in Bridgewater Associates, LP., the largest hedge fund in the world. Audio recording or filming of conversations and meetings, available to all employees to view is one way to encourage conversations of value for the company. "Under the Principle of Radical Transparency every meeting and conversation at Bridgewater, including personal reviews and Management Committee meetings, is filmed or recorded and archived in Bridgewater's library for review by any employee." 42

Recording communication is certainly one approach to the problem. However, coordination around strategic silence can also occur outside the recording realm, such as at social or private engagements; and as firms grow the required number of recordings and videos may prove costly to track and monitor. Bridgewater also has a baseball scorecard for each employee based on a weighted system of "dots." Marks or dots are scored as feedback based on interactions with others that are sent via a software application that employees access. An employee receives feedback quickly and often. ${ }^{43}$ However, the nature of strategic silence is such that it could remain under the radar of a "dot collector."

The conflict between silence and honest talk matters for all types of organizations, even regulators. "Apparently the SECs hierarchical culture was hoarded into 'Silos' which not only prevented the flow of information from one division to another, but also hindered the flow of information between management and staff." ${ }^{44}$ The lack of information flow among regulators that enabled Madoff to continue his fraud undetected is yet another example of information held back from observation that had damaging effects on a company, its investors, and others connected to the company's performance. ${ }^{45}$ Tent (2015) discusses the more general role of silos in preventing information flows.

\section{Unshared Knowledge: What Could Firms Do?}

Unshared knowledge compromises the usual levers for changing behavior such as promotions and compensation. In the classic pd game, the authorities knew the prisoners committed a crime, but when silence hides the

\footnotetext{
${ }^{37}$ Jordon, Hoffman, Bloom, and Rand (2016).

${ }^{38}$ Akerlof (2007).

${ }^{39}$ Our analysis considers willful blindness where knowledge of wrong doing or norm violation is deliberately ignored to protect the interests of the observers who could claim they did not "see" that anything was wrong as a distinct case because the transgression is known to the witnesses. See Hefferman (2011) for a discussion of Willful Blindness. However, the presence of willful blindness does not imply that all observations of silence fall into the willful ignorance category.

${ }^{40}$ Allcott (2011).

${ }^{41}$ Chwe (2001) p.21.

${ }^{42}$ Hess (2014 p.116.)

${ }^{43}$ Hess (2014 pp.147-155.)

${ }^{44}$ Lo (2016 p. 31.)

${ }^{45}$ See Markopolos (2010) for a riveting account of regulators not connecting the dots.
} 
knowledge that something is wrong the firm's capabilities to create a positive culture are seriously compromised. Mary Douglas's powerful insight about small communities where some foster trust and others do not, but that size alone guarantees little applies. ${ }^{46}$ Similarly, in the absence of common knowledge, resources devoted to the adoption of value and beliefs guarantee little.

The class of problems that reflect the choice of strategic silence needs a solution that goes beyond those currently available such as adding equity options to an employee's compensation package, ${ }^{47}$ or taping conversations. Of course there exist employees with strong emotional commitments to the firm who identify with it and behave as upstanding corporate citizens. ${ }^{48}$ But the screening of employees for personality traits and intelligence in order to find the type of person most likely to adopt the culturally transmitted values and beliefs of the firm is far from "foolproof." Firms should recognize that unshared knowledge creates human capital inefficiencies that finely tuned hiring practices or performance reviews will not prevent. The market offers limited assistance since while stock prices react to bad news events, unshared knowledge must add up to outcomes that are accurately assessed by investors.

An effectively functioning market requires what Martens calls a common knowledge interface, that is, a domain of generally shared information. If there is no such interface, then potential traders cannot mutually recognize their opportunities for gainful exchange. But to the extent that an agent derives expected profit from information which she has and which her exchange partners lack, it is in her interest that the common knowledge interface does not become all-encompassing. Each agent thus tends to have incentives to make limited contributions to the common knowledge interface. ${ }^{49}$

The need for firms to generate additional knowledge contributions should serve as the building block for an effective remedy. Recent technological developments have the potential to provide the foundation for a new type of remedy. For example, Bitcoin has inspired many variations of coins or tokens that enable token buyers to purchase a private key that gives them access to a decentralized database. As bitcoin offers a different platform for monetary exchanges, an intrafirm tokenized ecosystem has the potential to provide a different platform for rewards. ${ }^{50}$ As the example of strategic silence shows, the coworkers were in some sense 'free' to maintain silence when it goes undetected and protects the workers from penalties and instead generates a performance reward. A remedy must have the capability to make secrecy costly. It may be impossible to track every decision, but an appropriately designed system where workers get additional digital points for good behavior has the capability to offer incentives for contributions that add to shared knowledge. One solution is a to require a minimum number of points to get on a good actors' list. Those on the list would monetarily benefit and would need to continue to deposit points to stay on the list. ${ }^{51}$

Currently, digital tokens offer competition for traditional approaches for rewarding effort. For example, Earn.com, recently acquired by coinbase, rewards profile users in digital currency for replying to emails and completing microtasks. The company provides a broad and deep base of expertise available from venture capitalists to programmers to crypto investment advisors for users to query. ${ }^{52}$ Similarly, The Bounties Network offers tokens for the completion of tasks. ${ }^{53}$ Brave is a web browser that rewards users for their attention through attention tokens. ${ }^{54} \mathrm{~A}$ remedy that crowd sources reputation management through a properly designed token ecosystem redirects behavior by adding another incentive layer for employees to consider.

\footnotetext{
${ }^{46}$ Douglas (1986).

${ }^{47}$ See The Financial Crisis Inquiry Report $(2011$, p.63) on the role of options in compensation packages as yet another example of upside reward swithout any downside.

${ }^{48}$ Akerlof and Kranton (2005).

${ }^{49} \operatorname{Ross}(2014$ p. 102.)

${ }^{50}$ The original paper thatintroduces Bitcoin, Nakamoto (2009) includes a discussion of the incentives for mining bicoin and maintaining the system that creates trustless transactions for purposes of exchange.

${ }^{51}$ There are Token Curated Registries (TCRs) where the important characteristic of a TCR is that there must be a benefit or economic incentive from joining the list. See Goldin (2017), Gajek (2018), and de laRouviere (2017). The quality of the list is protected by those on the list.

${ }^{52}$ “"Create a verified Earn.com profile and joins lists based on skills and interests . . . earn bitcoin by answering paid emails and completing microtasks." earn.com.

${ }^{53} \mathrm{https} / / \mathrm{www}$.bounties.com.

${ }^{54}$ (www.Brave.com)

18
} 
For example, each worker could send tokens to other workers using a key that changes its address for each exchange so the identity of the worker sending the token is protected. The token score of each worker could be seen on a private blockchain. Newly interpreted analysis of the famous gorilla experiment, where that failure to see the gorilla crossing the screen is due not to a cognitive limitation but rather is the result of participants' focus on the goal of counting passes among those with a specific color shirt, provides another way to understand that the same potential exists for tokenized rewards. ${ }^{55}$ Simply getting employees focused on how to earn tokens directs behavior in ways that the tokenized eco-system is designed to encourage.

In the example of the loan approval process, each coworker's strategy choice would have to take into account implications for his token score, both present and future. Suppose the design is such that once a missed loan repayment occurs the coworkers may not use their tokens to stake a position on a good actors' list. Is silence still the best choice even in the presence of significant benefits from coalitional loyalty? The coworkers must consider whether applying for another job, or remaining at the company is worth it. The parameters can be chosen so that losing the chance to get on the good actor list is bad enough that the coworkers do not approve the loan even in the face of punishment for not making their numbers.

Strategic silence is also present in other circumstances. An example is when employees do not reveal the waste of time spent in meetings organized by a superior. It is present when subordinates fear calling out the poor performance of superiors, or experience in silence the dismissal of good ideas that challenge entrenched interests. As examples from Madoff to Wells Fargo to Enron show strategic silence often accompanies fraud.

A company could vary the payoffs to tokens according to an algorithm that would achieve specific objections. The design of a token platform could include the number of tokens to assign initially, the assessment and weight given to token feedback and even the potential to lose tokens as features. It is up to each firm to decide the kind of culture it wants and then to construct the software infrastructure compatible with its culture by designing its own private token system that can operate as a digital currency. Considering the rich datasets available that are harvested to map locations, inform vacation plans, recommend movies, find music and target books it is not much of a stretch to see this same process can work when it comes to designing an intra-firm tokenized eco-system.

\section{Concluding Comments}

There are many reasons why informal practices and norms that make up much of what is known as corporate culture are ineffective in building trust that employees will act in the firm's interests. The pd game is used to formalize a certain conception of a conflict where employees do not always say what they know. The pd game is not the only way to capture strategic silence, and if this formalization were eliminated the problem of strategic silence will remain. The main hurdle with building "A Virtuous Corporate Culture" is that while corporate culture provides informal practices and norms, as well as, official policies the corporate culture switch that turns on proper behaviors is often invisible. Many decisions, especially the decision to remain silent, fall under the surveillance radar and are not part of common knowledge. Invisible decisions create unshared knowledge for the firm.

Assigning cash flow rights to tokens for those employees who succeed in getting on a good actors' list is well within the technological possibilities that exist today. In the seminal paper by Jensen and Meckling (1976) stock ownership accomplished this goal. But as the long list of crises examined in the Financial Crisis Inquiry Report (2011) illustrate the ownership stakes have not worked as anticipated. A very different solution is to automate jobs where strategic silence is based on ignoring well-defined criteria, as in the loan approval example. But not all jobs that employees may respond to with strategic silence will be easy to replace, especially those involving subjective judgment.

At this stage, the most we can offer is a reasonable explanation for strategic silence and a reasonable path towards a solution. Software in the form of digital tokens is gaining traction as a viable source of rewards and economists need to take notice. One reason is that transferring current applications to fit the internal dynamics within firms requires careful economic analysis. Another is that tokens used for rewarding employees are an important step towards mapping authority and control that traditionally is centralized within a firm onto a decentralized platform. This development is a direct challenge to the conceptualization of the boundaries of the firm that needs attention in order to move the tokenization of assets onto the rigorous footing needed for policy analysis.

\footnotetext{
${ }^{55} \mathrm{Felin}(2018)$ https://aecon.po/essays/are-humans-really-blind-to the-gorilla-on-the-basketballcourt.
} 
Our main conclusion is that corporate culture, as a source of social rules, rests upon shaky grounds when it comes to common knowledge. Firms should take advantage of technological developments that offer an alternative platform to reward good actors through designing metrics in ways that stand to benefit significantly from additional economic analysis. Figuring out the levers to push to reduce the hoarding of value within a firm in the form of unexpressed knowledge can be approached using different methodologies. The tokenization of actions has practical value that awaits theoretical developments.

\section{Acknowledgements:}

The author is grateful to the participants at the $4^{\text {th }}$ International Conference of Philosophy and Economics, Lyon, France June 2018 for their comments. The author would also like to thank Ray Franklin and Harvey Gram for comments on an earlier draft. The author alone is responsible for any errors.

\section{References}

Akerlof, G. A. (2007). The Missing Motivation in Macroeconomics. American Economic Review, 97 (1): 5-36.

Akerlof, G. A., and R.E. Kranton, R. E. (2000). Economics and Identity. Quarterly Journal of Economics 105(3) 715-53.

Akerlof, G. A. and R.E. Kranton(2005). Identity and the Economics of Organizations. Journal of Economic Perspectives 19(1) 9-32.

Alchian, A. and H. Demsetz, H. (1972). Production, Information Costs, and Economic Organization. The American Economic Review 62(5) 777-795.

Allcott, H. (2011). Social Norms and Energy Conservation. Journal of Public Economics. 95 (9,10) 1082-1095.

Allspan, J. (2012). "Blameless PostMortems and a Just Culture". codeascraft.com/2012/05/22/blamelesspostmortems.

Artem, A., D. Retman, A. Denison and G. Cohen (eds). (2017). Muserum. White Paper.

Axelrod, R. (1984). The Evolution of Cooperation. (New York: Basic Books.)

B'enabou, R. J. and J. Tirole, (2016). Bonus Culture: Competitive Pay, Screening, and Multitasking. Journal of Political Economy 124(2) 305-370.

Brickley, J. A., C. Smith, C. and J. Zimmerman (2015). Managerial Economics and Organizational Architecture (New York: McGraw Hill Publishers.)

Chaplinsky, S. (2008). Bear Stearns and the Seeds of Its Demise. Harvard Business School Case Study.

Chwe, S. Y. M. (2001).Rational Ritual: Culture, Coordination, and Common Knowledge (New Jersey: Princeton University Press.)

Choi, J.K. and S. Bowles (2007). The coevolution of parochial altruism and war. Science 318, 636-640.

Coase, R. H. (1937). The Nature of the Firm. Econometrica 4(16) 386-405.

Cohn, A., E. Fehr, E. and M.A. Mar'echal (2014). Business culture and dishonesty in the banking industry. Nature 516, 86-89.

Cremer, J. (1993). Corporate Culture and Shared Knowledge, Industrial and Corporate Change 2, 351-386.

Curry O.S. (2016). Morality as Cooperation: A Problem-Centered Approach. Shackelford T., Hansen R. (eds) The Evolution of Morality (Springer, Cham: Evolutionary Psychology. )

De Hass, R. and V. Neeltj (2012). International Stock Transmission After the Lehman Brothers Collapse: Evidence from Syndicated Lending. American Economic Review 102.3, 231-237.

de la Rouviere, S.. (2017). Curation Markets. Retrieved from http://www.medium.com.

Douglas, M. (1986). How Institutions Think (Frank W. Abrams Lectures) (New York: Syracuse University Press.)

Dovidio, J. F. and S.I. Gaertner, (2010). Intergroup Bias Handbook of Social Psychology, edited by Susan T. Fiske, Daniel Gilbert and Gardner Lindsey (pp.1084-1121).

Dudley, W. (2018). Transcript of Banking Culture-Still Room for Improvement? Retrieved from www.newyorkfed.org/newsevents/speeches/2018/dud180209.

Eisenhardt, K. M. (1989). Agency Theory: An Assessment and Review. Academy of Management Review 14(1).

Fama E. F. and M. Jensen, M. (1983). Agency Problems and Residual Claims. The Journal of Law and Economics 26(2) 327-349.

Felin, T. (2018). Retrieved from https://aecon.po/essays/are-humans-really-blind-to-the gorilla-on-the basketballcourt. 
Financial Crisis Inquiry Commission. (2011). The Financial Crisis Inquiry Report.(New York: Public Affairs. ) G30 Working Group. (2015). "Banking Conduct and Culture: A Call for Sustained and Comprehensive Reform." Special Report.

Gajek, S. (2018). Graded Token-Curated Decisions with Up-Down voting- Designing Crypteconomic Ranking and Reputation Systems. Retrieved from https://www.Medium.com.

Garcia, J. and J.C.C.M Van den Bergh, (2011). Evolution of Parochial Altruism by Multilevel Selection. Evolution and Human Behavior 32(4), 277- 287.

Gaus, G. F. (2008). On Philosophy, Politics, and Economics (California: Wadsworth Cengage Learning.)

Gibson, R. C. Tanner, and A.F. Wagner. (2013). Preferences for Truthfulness: Heterogeneity among and within Individuals. American Economic Review 103 (1): 532-48.

Goldin, M. (2017). Token-Curated Registries 1.0. Retrieved from https://www.medium.com.

Guiso, L., .Sapienza, R, and L. Zingales, (2013). The Value of Corporate Culture. Working Paper.

Haidt, J. (2007). The new synthesis in moral psychology. Science 316, 998-1002.

Hall, T. (2012). A Toxic Culture Can be Hazardous to Your Bank's Balance Sheet. American Banker November 27.

Hammond, R. A. and Axelrod, R. (2006). The Evolution of Ethnocentrism.

Journal of Conflict Resolution 50, 926-936.

Hefferman, M. (2011). Why We Ignore the Obvious at Our Peril (New York: Walker Publishing Company.)

Hermalin, B. E. (2012). Leadership and Corporate Culture. Handbook of Industrial Economics, ed. Robert Gibbons and J. Roberts (Princeton, N.J.: Princeton University Press,) pp.432-478.

Hess, E. D. (2014). Learn or Die: Using Science to Build a Leading-Edge Learning Organization. (New York: Columbia University Press) pp.113-163.

Hodgson, G. M. (1996). Corporate Culture and the Nature of the Firm in John Groenewegen, ed., (Boston: Kluwer Academic Press.)

Hoffman, M,,E. Yoeli,, N.A. Dalkiran, M.A. Nowak, (2018). Why Norms are Categorical. PSAS In press.

Holmstrom, B. (1999). Managerial Incentive Problems: A Dynamic Perspective. Review of Economic Studies 66(1), 169-182.

Homanen, M. (2018). Depositors Disciplining Banks: The Impact of Scandals. Working Paper: Cass Business School City University of London.

Jensen, M. and W.H. Meckling (1976). Theory of the firm: Managerial Behavior, Agency Costs and Ownership Structure. Journal of Financial Economics 3(4) 305-360.

Jordan, J., M. Hoffman, P. Bloom, and D.G. Rand (2016). Third-party Punishment as a Costly Signal of Trustworthiness.Nature. Doi:10.1038/nature16981.

Kanter, R. M. (1993). Men and Women of the Corporation.(New York: Basic Books.)

Kreps, D. M. (1990). Corporate Culture and Economic Theory, in J. E. Alt and K. A. Shepsle, eds.,Perspectives on Positive Political Economy. Cambridge, England: Cambridge University Press.

Krouse, S. and K. Grind. (2018). "Fidelity May Abandon Its Star Stock- Picker System After Harassment." Wall Street Journal February 26.

Lazear, E. P. (1995). Corporate Culture and the Diffusion of Values In Trends in Business Organization. Horst Siebert, ed. Tubingen, Germany, pp. 134-40.

Leeson, N. (1996). Rogue Trader. (New York: Little, Brown and Company.)

Lo, A. (2016). The Gordon Geko Effect: The Role of Culture in the Financial Industry. Federal Reserve Bank of New York Economic Policy Review pp. 17-42.

Luce, D. and H. Raiffa, (1957). Games and Decisions. (New York: John Wiley and Sons.)

Markopolos, H. (2010). No One Would Listen: A True Financial Thriller (New York: Wiley Publishers.)

Masuda, N. (2012). In-group favoritism and intergroup cooperation under indirect reciprocity based on group reputation. Journal of Theoretical Biology 311, 8-18.

McNulty, J. E. and Akhigbe. A. (2015). Corporate Culture, Financial Stability and Bank Litigation. New York Federal Reserve Bank 1-83.

Meyer, M. and J. Vickers, (1997). Performance Comparisons and Dynamic Incentives, Journal of Political Economy 105(3), 547-581.

Mishkin, F. S (2011). Over the Cliff: From the Subprime to the Global Financial Crisis. Journal of Economic Perspectives 25(1): 49-70. 
Moosa, I. A. (2007).Operational Risk: A Survey Financial Markets, Institutions, and Instruments 16, 167-194.

Nakamoto, S. (2009). Bitcoin: A Peer-to-Peer Electronic Cash System.

Nowak, M. A. (2006). Five rules for the evolution of cooperation. Science 314(5805), 1560-1563. http://doi.org/10.1126/science.1133755.

Ohtsuki, H. and Y. Iwasa (2006). The leading eight: social norms that can maintain cooperation by indirect reciprocity. Journal of Theoretical Biology 239, 435-444.

Ohtsuki, H. and Y. Iwasa, (2009). Indirect reciprocity provides only a narrow range of efficiency for costly punishment. Nature 457, 79-82.

Rapoport, A. and A.M. Chammah. (1965). Prisoner's Dilemma: A Study in Conflict and Cooperation. (Michigan: University of Michigan Press.)

Ross, D. (2014). Philosophy of Economics. Palgrave MacMillian.

Reuters Staff. (2017). ”Banks Have Paid 321 billion in Fines Since Crisis:” March 2.

Robertson, D. (2011). So That's Operational Risk. Economics Working Paper 2011-1. Washington, DC: Office of the Comptroller of the Currency.

Salz Review (2013). An Independent Review of Barclay's Business Practices.

Shue, K. (2013). Executive Networks and Firm Policies: Evidence from the Random Assignment of MBA Peers. SSRN Working Paper.

Steam (2017). An Incentivized, blockchain-based, public content platform. White Paper August.

Tent, G. (2015).The Silo Effect. (New York: Simon \& Schuster Inc..)

Valukus,A.R..(2010). Report of Anton R. Valukus. Retrieved from https://en.wikipedia.org/wiki/ReportofAntonR.Valukas.

Williamson, O. E. (1979) Transaction-Cost Economics: The Governance of Contractual Relations. Journal of Law and Economics 22(2), 233-261.

Williamson, O. E. (1983) Markets and Hierarchies (New York: Free Press. )

Willmer, S. (2017).”Dark Side at Fidelity: Women Describe Culture of Bias, Revenge.” Bloomberg Business. 